\title{
Simultaneous Design, Scheduling, and Optimal Control of a Methyl-Methacrylate Continuous Polymerization Reactor
}

\author{
Sebastian Terrazas-Moreno, Antonio Flores-Tlacuahuac* \\ Departamento de Ingeniería y Ciencias Químicas, Universidad Iberoamericana \\ Prolongación Paseo de la Reforma 880, México D.F., 01210, México \\ Ignacio E. Grossmann \\ Department of Chemical Engineering, Carnegie-Mellon University \\ 5000 Forbes Av., Pittsburgh 15213, PA
}

December 17, 2007

${ }^{*}$ Author to whom correspondence should be addressed. E-mail: antonio.flores@uia.mx, phone/fax: $+52(55) 59504074$, http://200.13.98.241/ antonio 


\begin{abstract}
This work presents a Mixed-Integer Dynamic Optimization (MIDO) formulation for the simultaneous process design, cyclic scheduling, and optimal control of a Methyl Methacrylate (MMA) continuous stirred-tank reactor (CSTR). Different polymer grades are defined in terms of their molecular weight distributions, so that state variables values during steady states are kept as degrees of freedom. The corresponding mathematical formulation includes the differential equations that describe the dynamic behavior of the system, resulting in a MIDO problem. The differential equations are discretized using the simultaneous approach based on orthogonal collocation on finite elements, rendering a Mixed Integer Non-Linear programming (MINLP) problem where a profit function is to be maximized. The objective function includes product sales, some capital and operational costs, inventory costs, and transition costs. The optimal solution to this problem involves design decisions: flow rates, feeding temperatures and concentrations, equipment sizing, variables values at steady state; scheduling decisions: grade productions sequence, cycle duration, production quantities, inventory levels; and optimal control results: transition profiles, durations, and transition costs. The problem was formulated and solved in two ways: as a deterministic model and as a two-stage programming problem with hourly product demands as uncertain parameter described by discrete distributions.
\end{abstract}




\section{Introduction}

Design, scheduling and control of chemical processes are complex problems which are usually approached independently. Typically, the design phase is carried out first, and scheduling and control problems are solved once the process design has been solved. In the first step, the design is carried out with certain goals regarding capacity, profitability, environmental and safety concerns, while in a later step scheduling and control problems are solved during process operation, usually with the objective of minimizing costs or maximizing profit. This approach results in the loss of certain degrees of freedom due to the sequential solution of the three problems, which in turn might render suboptimal results for the overall process synthesis ${ }^{1}$. For this reason, the simultaneous solutions of design and control ${ }^{2,3,4}$, scheduling and design ${ }^{5,6,7,8}$, and scheduling and control problems ${ }^{9,10,11,12,13,14,15,16}$ have been the subject of some works.

Determination of the optimal equipment dimensions and steady state operating conditions as part of an independent design phase, has the risk of resulting in poor operability conditions, and inadequate process control due to the decreased degrees of freedom. In previous works ${ }^{3,4}$ the problem of simultaneously determining some process design variables, steady states and control structures has been addressed, and its solution has been put into practice in processes involving grade transitions in polymerization reactors. Another recent work by Asteasuain et al. ${ }^{2}$ is relevant for the present work, since it deals with the simultaneous process and control system design of a multi-grade continuous polymerization reactor. The design problem concerns the determination of process equipment, control structures and tuning parameters, as well as the choice of reaction initiator. From the perspective of the present work, it should be noted that the steady states that correspond to the different grade producing operations are also determined as part of the design problem. Simultaneously, optimal transition trajectories between those steady states are also evaluated as part of the control problem.

Simultaneous design and scheduling is also a common problem in the Process Systems 
Engineering literature. A detailed review involving scheduling and design of batch processes is available elsewhere ${ }^{5}$. Optimizing highly non-linear and non-convex processes poses many challenges, especially since many local optimal solutions can be present. Heo et. $\mathrm{al}^{6}$ address this problem using an evolutionary design method that performs a search near the optimal solution found by adding equipment units to the resulting configuration. However, the rigorous global solution to the design and scheduling problem in non-linear, non-convex problems remains a major challenge.

The robustness and flexibility of a process design is of major concern to process engineers. One common approach in practice is to over-design so as to guarantee feasibility of operating conditions for many possible scenarios. Obviously this approach has the disadvantage of producing suboptimal solutions for the expected range of values of the uncertain process conditions. Two main approaches have been used for the solution of process design under uncertainty ${ }^{5}$ : the so-called deterministic and stochastic approaches. The first one involves a min-max formulation in the objective or in the constraints to guarantee flexible operation for a range of uncertain parameters. In the stochastic approach $^{17}$ the optimization of an expected value function based on distribution functions of the uncertain parameters is undertaken using two or multi stages stochastic programming formulations $^{18,19}$. For the case of discrete distributions the deterministic equivalent of a two-stage programming problem yields a formulation that is equivalent to a multiperiod design problem ${ }^{5}$. Another stochastic formulation is the so-called probabilistic or chance constraint framework ${ }^{20,21,22}$. In this latter approach, rather than considering the optimization of an expected value function, the idea is to compute optimal conditions under which a given constraint has the maximum probability to be met. We address in the present work the simultaneous design, scheduling, and control of polymerization reactors under uncertainty using a two-stage programming multiperiod approach for dealing with discrete uncertainty.

The topic of simultaneous scheduling and control (or dynamic optimization) is the subject of recent works. A comprehensive literature review on the subject literature can be found 
in a recent paper by Terrazas-Moreno et. $\mathrm{al}^{9}$. The basis of all solution methods is the discretization of the differential equations that describe dynamic behavior, and the addition of the resulting non-linear algebraic equations into a scheduling formulation resulting in MINLP problems.

The simultaneous solution of design, scheduling and optimal control under uncertainty has been studied very little. The present work has the objective of simultaneously determining the optimal solution of these problems for a continuous polymerization reactor, operating under a cyclic schedule assumption, and for which the simultaneous dynamic optimization (SDO) technique is used ${ }^{23}$. Uncertainty in grade demand is handled in one of the two case studies using a two-stage programming formulation with uncertain demands represented by discrete distributions. Two similar works are those presented by Bhatia and Biegler ${ }^{7,8}$, in which the dynamic optimization for batch design and scheduling is solved. The main differences with the work of these authors is that no steady states are calculated as part of the solution to the design problem, and that the uncertainties are restricted to kinetic parameters.

The paper is organized as follows. In a first part, the problem is defined, detailing all assumptions, and the optimization formulation is developed. This formulation is based on previous work by our research group ${ }^{9}$. In a second part two case studies are presented: the first one assumes deterministic values for all parameters, while the second includes different scenarios depending on the realization of grade demand uncertainty from a set of possible discrete values. Finally, conclusions and future research directions are presented.

\section{Problem definition}

A given number of polymer grades, specified in terms of molecular weight distributions are to be manufactured using an industrial reaction system. The present work is concerned with simultaneously determining the design for the reaction process, the cyclic manufacturing operation, and the control profile during grade transitions that feature 
optimality conditions. Since no process design is known a priori, the process steady states corresponding to different grade production conditions must be determined as part of the solution. The problem is solved using a Mixed Integer Dynamic Optimization (MIDO) approach in which the economic profit is to be maximized. The objective function includes the following terms: sales, inventory costs, transition costs, capital costs, and steady state operation costs. The design parameters are taken as the reactor and jacket volumes, the feed and cooling water flow rates and their respective temperatures, as well as the monomer and initiator feed stream concentrations. The steady states describing each polymer grade are also determined as part of the design. On the other hand, the schedule is described by the sequencing of grades, the production mix, the duration of the production runs, and the overall cycle duration. Finally, the control decisions involve the optimal grade transitions and their duration, during which the initiator flow rate is the manipulated variable.

The formulation includes the following assumptions: (a) Inventory, raw material, kinetic parameters and utilities costs are deterministic parameters; (b) no model mismatch or process perturbations are considered; (c) polymer production is bounded between the minimum amount to satisfy grade demand, and an upper bound on this quantity, since in almost all cases it is possible to sell a certain amount of overproduction, especially when dealing with polymer products with high demand; (d) all grades are produced only once during the production cycle; (e) once a grade has been produced it is stored and depleted until the end of the cycle; (f) once a production wheel is finished it is immediately and indefinitely repeated. In this way grade inventories allow the constant consumption of a product until it is produced again, so that no product shortages occur. The mathematical model, also assumes that the set of differential equations that describes the dynamic behavior of the system, accurately models the process over all the range of conditions used, which is a reasonable assumption. For instance, the model presented in the case study has been previously used under similar conditions, and it will be assumed to correctly approximate the polymerization process under the relevant conditions. 
Although the problem formulation involves many significant simplifications, the need for a robust process design able to deal with uncertainty in some parameters is not overlooked. In this work uncertainty in product demands is handled through a two-stage multiperiod formulation.

\section{Design, Scheduling and Control MIDO Formula- tion}

The problem is solved using a MIDO formulation based on the simultaneous scheduling and control (SSC) formulation proposed by our research group ${ }^{9}$. As in previous works, ${ }^{9,10,11}$ the manufacturing operation is carried out in production cycles. The cycle time is divided into a series of slots. Within each slot two operations are carried out:

(a) the production period during which a given product is manufactured around steadystate conditions, and (b) the transition period during which dynamic transitions between two products take place. The description of the formulation proposed in this work is divided according to the characteristics of its different sections (objective function, design, scheduling and optimal control). The notation is listed in detail in the appendix.

\section{- Objective Function}

$$
\begin{aligned}
\max & \left\{\sum_{i=1}^{N_{p}} \frac{C_{i}^{p} W_{i}}{T_{c}}\right. \\
& -\alpha \frac{V^{\beta}}{a t}-F \rho C p\left(T_{i n}-T_{a m b}\right) C^{s t}-F_{c w} \rho_{w}\left(C^{c w}+\frac{C p_{c w}\left(T_{j}^{*}-T_{w}\right)}{\lambda_{h v}} P_{e w} C^{m w}\right) \\
& -\sum_{i=1}^{N_{p}} \frac{C_{i}^{s}\left(G_{i}-W_{i} / T_{c}\right) \Theta_{i}}{2} \\
& \left.-\sum_{k=1}^{N_{s}} \theta_{k}^{t} F_{\text {mon }} C_{\text {min }} M W_{m o n} \frac{C^{r}}{T_{c}}-\left[\sum_{k=1}^{N_{s}} \sum_{f=1}^{N_{f} e} h_{f k} \theta_{k}^{t} C_{\text {Iin }} M W_{i n i} \sum_{c=1}^{N_{c p}} F_{f c k}^{I} \gamma_{c}\right] \frac{C^{I}}{T_{c}}\right\}
\end{aligned}
$$


The total process profit is given by the income of the manufactured products minus the sum of some capital costs, operation costs, inventory costs and the product transition costs. All terms are calculated on an hourly basis and are divided by the cyclic time $\left(T_{c}\right)$ so that the objective function value corresponds to the cyclic hourly profit. The first term represents the amounts sold of each grade $\left(W_{i}\right)$, times their respective prices $\left(C_{i}^{p}\right)$ divided by cycle duration $\left(T_{c}\right)$. The second, third and fourth terms in the objective function represent the capital an operating costs related to design decisions. The second term corresponds to reactor costs, considering a four year amortization ${ }^{2}$, where $\alpha V^{\beta}$ is a correlation of the equipment costs between 0.05 and $5 \mathrm{~m}^{3,24}$. The denominator at provides the hourly cost corresponding to the above mentioned amortization time. The third term is related to the costs of heating the feed stream from room temperature $T_{a m b}$ up to the desired feeding temperature $T_{i n}$, where $F$ is the feed stream flow rate, $\rho$ is the feed stream density, and $C p$ is its specific heat. The fourth term quantifies the costs related to cooling water. $F_{c w} \rho_{w} C^{c w}$ is the cost of supplying cooling water to the reactor. $\frac{C p_{c w}\left(T_{j}^{*}-T_{w}\right)}{\lambda_{h v}} P_{e w} C^{m w}$ represents the cost of the cooling water lost during cooling tower operation, where $C p_{c w}$ is the specific heat of water, $T_{j}^{*}$ is an expected average temperature of the jacket, $T_{w}$ is the room temperature of water, $\lambda_{h v}$ is the latent heat of vaporization, $P_{e w}$ is an average fractional loss of water due to vaporization and finally, $C^{m w}$ is the unit cost of cooling water.

The remaining terms correspond to inventory and transition costs, as explained in detail in a previous work ${ }^{9}$.

1. Design formulation.

a) Bounds on design variables:

The CSTR and process variables were bounded somewhere around the nominal values reported by Silva-Beard et al. ${ }^{25}$. 


$$
\begin{aligned}
0.050 \mathrm{~m}^{3} & \leqslant \quad \leqslant 5 \mathrm{~m}^{3} \\
0.010 \mathrm{~m}^{3} / \mathrm{h} & \leqslant F_{m o n} \leqslant 20 \mathrm{~m}^{3} / \mathrm{h} \\
0.010 \mathrm{~m}^{3} / \mathrm{h} & \leqslant F_{c w} \leqslant 20 \mathrm{~m}^{3} / \mathrm{h} \\
0.010 \mathrm{kgmol} / \mathrm{m}^{3} \leqslant C_{\text {min }} & \leqslant 10 \mathrm{kgmol} / \mathrm{m}^{3} \\
0.010 \mathrm{kgmol} / \mathrm{m}^{3} & \leqslant C_{\text {Iin }} \leqslant 10 \mathrm{kgmol} / \mathrm{m}^{3} \\
300 \mathrm{~K} & \leqslant T_{i n} \leqslant 400 \mathrm{~K} \\
273 \mathrm{~K} & \leqslant T_{w 0} \leqslant 298 \mathrm{~K} \\
0 & \leqslant \quad \leqslant 0.5
\end{aligned}
$$

b) Equipment sizing relationships:

$$
\begin{aligned}
V_{0} & =\frac{1}{5} V \\
A & =9.2995 \mathrm{~V}^{2 / 3}
\end{aligned}
$$

Equation 3a states that the Jacket volume is one fifth of the reactor volume, while equation $3 \mathrm{~b}$ expresses the geometrical relationship between the reactor volume and its surface area, where heat exchange takes place.

c) Steady States:

$$
0=f^{n}\left(x_{s s}^{1}, \ldots, x_{s s}^{n}, u_{s s}^{1}, \ldots u_{s s}^{m}, \mathbf{p}\right), \forall n
$$

Equation 4 represents the dynamic model equations set to zero, denoting a 
steady state. Variables $x_{s s}^{n}$ and $u_{s s}^{n}$ represent the values of the system states and manipulated variables at steady state, whereas $\mathbf{p}$ stands for the design parameters as described previously.

The variables selected as design variables strongly influence both capital and operating costs. In our formulation we assume that capital costs are mainly related to reactor volumes. On the other hand, operating costs are mainly driven by cost of raw materials (flow rate and temperature of monomer and initiator) and auxiliary services (cooling water flow rate and temperature).

2. Scheduling formulation.

The scheduling formulation has been described in detail in previous works ${ }^{9,11}$, except for equation $6 \mathrm{~b}$. This equation establishes an upper bound on production $\left(U^{p}\right.$, chosen as one and half times the minimum demanded quantity). It is assumed that some considerable (but not unlimited) amount of product can be sold, over the minimum demand to be satisfied.

a) Product assignment:

$$
\begin{aligned}
& \sum_{k=1}^{N_{s}} y_{i k}=1, \forall i \\
& \sum_{i=1}^{N_{p}} y_{i k}=1, \forall k
\end{aligned}
$$

where

$y_{i k} \quad$ Binary variable to denote if product $i$ is produced at slot $k$ 
b) Amounts manufactured:

$$
\begin{aligned}
W_{i} & \geqslant D_{i} T_{c}, \forall i \\
W_{i} & \leqslant U^{p} D_{i} T_{c}, \forall i \\
W_{i} & =G_{i} \Theta_{i}, \forall i \\
G_{i} & =F_{i}^{o} C_{m 0} \frac{M W_{\text {monomer }}}{1000}, \forall i
\end{aligned}
$$

c) Processing times:

$$
\begin{aligned}
\theta_{i k} & \leqslant \theta^{\text {max }} y_{i k}, \forall i, k \\
\Theta_{i} & =\sum_{k=1}^{N_{s}} \theta_{i k}, \forall i \\
p_{k} & =\sum_{i=1}^{N_{p}} \theta_{i k}, \forall k
\end{aligned}
$$

e) Timing relations:

$$
\begin{aligned}
t_{k}^{e} & =t_{k}^{s}+p_{k}+\theta_{k}^{t}, \forall k \\
t_{k}^{s} & =t_{k-1}^{e}, \forall k \neq 1 \\
t_{k}^{e} & \leqslant T_{c}, \forall k \\
t_{f c k} & =(f-1) \frac{\theta_{k}^{t}}{N_{f e}}+\frac{\theta_{k}^{t}}{N_{f e}} \gamma_{c}, \forall f, c, k
\end{aligned}
$$

3. Dynamic Optimization formulation.

To address the optimal control part, the simultaneous approach ${ }^{23}$ for addressing dynamic optimization problems was used in which the dynamic model representing 
the system behavior is discretized using the method of orthogonal collocation on finite elements ${ }^{26,27}$. According to this procedure, a given slot $k$ is divided into a number of finite elements. Within each finite element an adequate number of internal collocation points is selected. Using several finite elements is useful to represent dynamic profiles with non-smooth variations. Thus, the set of ordinary differential equations comprising the system model, is approximated at each collocation point leading to a set of nonlinear equations that must be satisfied.

a) Dynamic mathematical model discretization:

$$
x_{f c k}^{n}=x_{o, f k}^{n}+\theta_{k}^{t} h_{f k} \sum_{l=1}^{N_{c p}} \Omega_{l c} \dot{x}_{f l k}^{n}, \forall n, f, c, k
$$

Also note that in the present formulation the length of all finite elements is the same and computed as,

$$
h_{f k}=\frac{1}{N_{f e}}
$$

b) Continuity constraint between finite elements:

$$
x_{o, f k}^{n}=x_{o, f-1, k}^{n}+\theta_{k}^{t} h_{f-1, k} \sum_{l=1}^{N_{c p}} \Omega_{l, N_{c p}} \dot{x}_{f-1, l, k}^{n}, \forall n, f \geqslant 2, k
$$

c) Model behavior at each collocation point:

$$
\dot{x}_{f c k}^{n}=f^{n}\left(x_{f c k}^{1}, \ldots, x_{f c k}^{n}, u_{f c k}^{1}, \ldots u_{f c k}^{m}\right), \forall n, f, c, k
$$

d) Initial and final controlled and manipulated variable values at each slot: 


$$
\begin{aligned}
x_{i n, k}^{n} & =\sum_{i=1}^{N_{p}} x_{s s, i}^{n} y_{i, k}, \forall n, k \\
\bar{x}_{k}^{n} & =\sum_{i=1}^{N_{p}} x_{s s, i}^{n} y_{i, k+1}, \forall n, k \neq N_{s} \\
\bar{x}_{k}^{n} & =\sum_{i=1}^{N_{p}} x_{s s, i}^{n} y_{i, 1}, \forall n, k=N_{s} \\
u_{i n, k}^{m} & =\sum_{i=1}^{N_{p}} u_{s s, i}^{m} y_{i, k}, \forall m, k \\
\bar{u}_{k}^{m} & =\sum_{i=1}^{N_{p}} u_{s s, i}^{m} y_{i, k+1}, \forall m, k \neq N_{s}-1 \\
\bar{u}_{k}^{m} & =\sum_{i=1}^{N_{p}} u_{s s, i}^{m} y_{i, 1}, \forall m, k=N_{s} \\
u_{1,1, k}^{m} & =u_{i n, k}^{m}, \forall m, k \\
x_{o, 1, k}^{n} & =x_{i n, k}^{n}, \forall n, k \\
x_{t o l, k}^{n} & \geqslant x_{N f e, N c, k}^{n}-\bar{x}_{k}^{n}, \forall n, k \\
-x_{t o l, k}^{n} & \leqslant x_{N f e, N c, k}^{n}-\bar{x}_{k}^{n}, \forall n, k
\end{aligned}
$$

e) Lower and upper bounds on the decision variables

$$
\begin{aligned}
& x_{\text {min }}^{n} \leqslant x_{f c k}^{n} \leqslant x_{\text {max }}^{n}, \forall n, f, c, k \\
& u_{\text {min }}^{m} \leqslant u_{f c k}^{m} \leqslant u_{\text {max }}^{m}, \forall m, f, c, k
\end{aligned}
$$


f) Smooth transition constraints

$$
\begin{aligned}
u_{f, c, k}^{m}-u_{f, c-1, k}^{m} & \leqslant u_{\text {cont }}^{c}, \forall m, k, c \neq 1 \\
u_{f, c, k}^{m}-u_{f, c-1, k}^{m} & \geqslant-u_{c o n t}^{c}, \forall m, k, f, c \neq 1 \\
u_{f, 1, k}^{m}-u_{f-1, N f e, k}^{m} & \leqslant u_{\text {cont }}^{f}, \forall m, k, f \neq 1 \\
u_{f, 1, k}^{m}-u_{f-1, N f e, k}^{m} & \geqslant-u_{\text {cont }}^{f}, \forall m, k, f \neq 1 \\
u_{1,1, k}^{m}-u_{i n, k}^{m} & \leqslant u_{\text {cont }}^{f}, \forall k \\
u_{1,1, k}^{m}-u_{i n, k}^{m} & \geqslant-u_{\text {cont }}^{f}, \forall k
\end{aligned}
$$

Equations 24- 29 force the change between adjacent collocation points and finite elements to be within a certain acceptable range.

\section{Two-stage programming approach for uncertainty in demand}

In general, scheduling and optimal control problems, due to their nature, are able to handle uncertainties from one scheduling period to the next. In other words, if uncertainties are present at the beginning of each scenario, and remain fixed throughout it, then the scheduling and the optimal control problems can be solved once for each scenario in order to accommodate each uncertainty realization. On the other hand, the design problem can only be solved once, and the design variable values, obtained from the solution cannot be changed throughout the different scenarios. In this work we assume that product demands are subject to uncertainties that are expressed as discrete distributions for hourly product demands, which give rise to the different scenarios. The simultaneous design, scheduling and optimal control problem is then formulated as a two-stage programming problem, in which the scheduling and optimal control are selected in stage 2 for each scenario. The context of uncertainty used in this paper is similar to the perfect information context presented by Bhatia and Biegler ${ }^{8}$, in which once a design is implemented changes in scheduling and optimal control can be made from scenario to scenario, based on the fact that complete (perfect) information about demand uncertainties is resolved before 
every cycle begins.

An important assumption must be made in order to be able to use the proposed twostage programming approach. In cyclic scheduling, products are consumed constantly throughout the cycle, and part of every product inventory carries over into the next cycle, until production of the relevant product begins again. In this context, changing the schedule order of production may cause product shortages if the production period of this product begins later in the new cycle than in the previous one. In this work it is assumed that a schedule switch caused by a change in demand scenario (if necessary) happens only once in a large number of cycles. In fact, the number of cycles is assumed to be large enough such that shortages that might occur during schedule switches need not be modeled in the formulation.

The two-stage programming formulation in this work is similar to that used by Bhatia and Biegler ${ }^{8}$, and it has the following form:

$$
\max \sum_{q=1}^{N d s} \omega_{q} \phi_{q}\left(x_{q}, u_{q}, s c_{q}, d, \theta_{q}\right)
$$

s.t.

$$
\begin{gathered}
h_{q}^{z}\left(x_{q}, u_{q}, s c_{q}, d\right)=0 \\
g_{q}^{z}\left(x_{q}, u_{q}, s c_{q}, d\right) \leqslant 0 \\
h_{q}^{s c}\left(s c_{q}, d, \theta_{q}\right)=0 \\
g_{q}^{s c}\left(s c_{q}, d, \theta_{q}\right) \leqslant 0 \\
h^{d}(d)=0 \\
d_{\text {min }} \leqslant d \leqslant d_{\max } \\
u_{q}, x_{q} \in Z, s c_{q} \in S C, d \in D, \theta_{q}=\left(\theta_{q}^{1} \ldots \theta_{q}^{N d s}\right)
\end{gathered}
$$


The set $q$, corresponds to each different demand scenario, and $\omega_{q}$, is the probability that a demand scenario $q$ will occur. Optimal control state variables and manipulated variables are designated as $x_{q}$ and $u_{q}$ respectively, $s c_{q}$ are scheduling variables, $d$ are design variables, and $\theta_{q}$ represents the uncertain parameters, in this case the product demands. Different scenarios have different scheduling and optimal control solutions, but are linked by a fixed set of design variables.

\section{Case Studies}

In the following section the proposed formulation is used to solve the simultaneous design, scheduling and optimal control of a MMA polymerization reactor, where different polymer grades are produced. First, the problem is solved as deterministic problem. In a second case, uncertainty in three of five polymer grade demands is taken into account, and the problem is solved using a two-stage programming formulation.

\section{MMA polymerization}

The MMA polymerization system used in this paper is that described by Silva-Beard et al. ${ }^{25}$. The polymerization reactions take place in a CSTR. The variables that correspond to the reactor design are bounded around the nominal values used in the above mentioned work $^{25}$. Table 2 shows kinetic constants and other relevant physical constants used in the mathematical model that describes the bulk free-radical MMA polymerization using AIBN as the initiator. This model is described below: 


$$
\begin{aligned}
\frac{d C_{m}}{d t} & =-\left(k_{p}+k_{f m}\right) C_{m} P_{o}+\frac{F\left(C_{m i n}-C_{m}\right)}{V} \\
\frac{d C_{I}}{d t} & =-k_{I} C_{I}+\frac{F_{I} C_{\text {Iin }}}{V}-\frac{F C_{I}}{V} \\
\frac{d T}{d t} & =\frac{(-\Delta H) k_{p} C_{m}}{\rho C_{p}} P_{0}-\frac{U A}{\rho C_{p} V}\left(T-T_{j}\right)+\frac{F\left(T_{i n}-T\right)}{V} \\
\frac{d D_{0}}{d t} & =\left(0.5 K_{t c}+k_{t d}\right) P_{0}^{2}+k_{f m} C_{m} P_{0}-\frac{F D_{0}}{V} \\
\frac{d D_{1}}{d t} & =M_{m}\left(k_{p}+k_{f m}\right) C_{m} P_{0}-\frac{F D_{1}}{V} \\
\frac{d T_{j}}{d t} & =\frac{F_{c w}\left(T_{w 0}-T_{j}\right)}{V_{0}}+\frac{U A}{\rho C_{p w} V_{0}}\left(T-T_{j}\right) ;
\end{aligned}
$$

where

$$
\begin{gathered}
P_{0}=\sqrt{\frac{2 f^{*} C_{I} k_{I}}{k_{t d}+k_{t c}}} \\
k_{r}=A_{r} e^{-E / R T}, r=p, f m, I, t d, t c
\end{gathered}
$$

The average molecular weight distribution of the polymer is defined as the ratio $D_{1} / D_{0}$. Five different MMA grades with different molecular weights are produced, where each grade corresponds to a different steady state. In this work, the only grade parameter fixed a priori is the desired average molecular weight distribution. The values of the state variables in the steady states that correspond to each desired molecular weight are kept as degrees of freedom. The desired average molecular weight distributions are 15000, 20000, 25000, 35000, and 45000 .

\subsection{Deterministic approach}

Under this case, all the parameters are assumed to be deterministic. Equations 1 to 29 are used directly to solve the simultaneous design, scheduling and optimal control of the MMA polymerization CSTR. Information about each desired grade is shown in Table 3. Results were obtained using the MINLP solver DICOPT ${ }^{28}$, based on the outer approximation algorithm ${ }^{29}$ through the GAMS modeling system. The problem consisted of 5000 continuous variables and 25 binary variables, and its solution took 1855 CPU s in a 
2.86 GHz machine. Tables 4 and 5 show the values of all design variables at the optimal solution point. Table 6 contains the scheduling variables that describe the optimal cycle, including hourly profit, while Figures 1(a)-1(c) show the optimal dynamic profiles during grade transitions. Table 7 shows the different contributions of each term in the objective function.

It is interesting to notice how the largest contribution to the costs are related to the design as seen from Table 7 . This indicates that any decision taken to decrease the design costs would involve an undesirable trade-off in the transition and inventory costs. For instance, a smaller reactor or feed stream flow rate would decrease the design costs, but the production rate would necessarily be smaller, which in turn would increase the cycle time and inventory costs.

On the other hand, the resulting optimal schedule $(A E D C B)$ is dominated by transitions between grades that have similar molecular weights, occurring in the direction of higher molecular weight to lower molecular weight, except of course, for the A to E transition, required at the beginning of the cycle. We have analyzed this type of transitions in detail in previous works ${ }^{9,10}$. From a dynamic point of view, transitions between grades with similar molecular weights are fast, since they involve similar steady state operating conditions (see Table 5). A long transition is allowed to occur in order to allow all other transitions to take place faster between similar grades ${ }^{9}$. Another important dynamic behavior is the shutting down of initiator feed stream. Since the AIBN initiator is expensive, transitions that involve shutting down initiator flow rate to the reactor result in little AIBN wasted during transitions. As a final observation, it is interesting to see that the resulting dynamic operation does not involve significant temperature change, approximating an isothermal process. 


\subsection{Two-stage programming approach for different demand sce- narios.}

In the second example uncertainty is introduced in the hourly demands of grades A, C, and E. In real life operations, uncertain demand is a continuous quantity, which can usually be described by a probabilistic distribution, but in this work, uncertainty in grade demand is handled through a set of discrete values which represent different demand scenarios. The problem is solved by using a two-stage programming approach for optimal design under uncertainty ${ }^{5}$, in which each period represents a different demand scenario, and where the objective function represents a weighted sum of the different possible scenarios. These scenarios are independent from each other, except for the set of design variables that remain constant throughout all of them ${ }^{8}$. The rigorous procedure for flexibility analysis would call for a second step in which the optimal design is tested all over the uncertain demand parameters domains ${ }^{5}$. The critical feasibility points would then be included as part of the finite set of possible values for the uncertain parameters, and solved within the multiscenario formulation, generating an iterative procedure. This procedure will not be included in this paper. The discretized demand values include significant variations from the nominal point, and although feasibility within the continuous domain established by the extreme demand values cannot be rigorously guaranteed, the results from the multiscenario formulation will show that finding critical feasibility points corresponding to intermediate demand values is unlikely. The application of large scale MINLP algorithms ${ }^{30}$ could allow a more exhaustive feasibility check for the computed optimal solution along with other interesting possibilities, listed later in this paper.

The example described below involves five different demand scenarios where low and high demand values for grades $\mathrm{C}$ and $\mathrm{E}$ are combined (demands for grade $\mathrm{B}$ and $\mathrm{D}$ remain constant), generating four scenarios. An extreme demand combination involving a significant change in demand for grade A generates the fifth scenario.

The different demand scenarios with corresponding discrete probabilities are detailed 
in Table 8. In order to efficiently solve the multiscenario formulation, it is initialized with the independent solutions to each demand scenario ${ }^{8}$. In other words, each scenario is solved as a deterministic problem, and the different solutions are passed on to initialize the two-stage programming problem. The multiscenario problem was solved using the MINLP solver DICOPT ${ }^{28}$, based on the outer approximation algorithm ${ }^{29}$ through the GAMS modeling system. The problem consisted of 24704 continuous variables and 125 binary variables, and its solution took 87,676 CPU s $(\sim 24 \mathrm{~h})$ in a $2.86 \mathrm{GHz}$ machine using a full space solution approach (i.e. no decomposition optimization technique was used). Tables 9, and 10 show the values of all design variables at the optimal solution. Table 11 show the objective function value and other relevant values for the description of each period solution, within the two-stage programming formulation.

As shown in Tables 4 and 9 the differences in terms of the CSTR design variables are in the feed stream flow rate, monomer concentration and reactor size (which in turns determines the area and volume of the jacket). However, the steady states determined through both approaches are very similar. The first scenario or period of the two-stage programming approach, corresponds to the deterministic problem. The solutions found by both approaches for the same scenario show different sequences, cycle durations and slightly different distribution of costs as shown in Table 11. The hourly profit of this particular scenario is lower in the two-stage programming solution than in the deterministic solution. Intuitively, one would expect that this decreased profit for the multiscenario solution, in scenario one, when compared against the deterministic solution is compensated by a better performance in other demand scenarios. The results are found in Table 12 . The overall profit (taking into account probabilities of each scenario) obtained by choosing the two-stage programming design is only slightly better than the one found using the deterministic approach. However, size and non-convexity of both problems are different, and as with every non-linear, non-convex problem, local optimal points are present. A way to compare both solutions in similar conditions was necessary before stating conclusions. The main expected advantage of the two-stage programming formulation over 
the deterministic solution is a more robust design. In some cases a certain design found to be optimal for a deterministic problem might not be feasible (let alone optimal) for all expected conditions. Being this case, a relevant comparison would involve comparing the deterministic design vs. the two-stage programming design, using the same problem conditions. This means that design variables found through both methods could be fixed and the same scheduling and optimal control problem could then be solved using both designs.

The results shown in Table 12 and 13 correspond to the proposed approach: they are the result of using as fixed designs those found by the deterministic and two-stage programming approaches, and solving each period independently as a scheduling and optimal control problem. The solution to example 1 in this paper (the original deterministic problem) was used as initialization point for all scenarios and for both designs. In this comparison it is clear that the design obtained from the two-stage programming formulation performs better than the one obtained by using the deterministic approach. It is worth noting that, in both cases, the production sequence is the same in all scenarios. The main differences are found in total transitions durations and cycle times. In Figures 1(a) to 2(c) one can see that most transitions have similar durations, except for the transition corresponding to slot 3 for both cases (in both cases this transition corresponds to a $D \rightarrow C$ transition). Cycle time differences can be attributed to faster transitions and to faster process rates in the two-stage programming formulation.

A summary of how the two-stage programming approach compares against the deterministic approach is presented in Figure 3. From this figure one can see that there is a clear trend in which, as total hourly demand (summation over all polymer grades) increases, the two stage programming approach performs better than the deterministic approach. 


\section{Conclusions}

The optimization formulation presented in this paper successfully addressed the simultaneous design (including steady state determination), cyclic scheduling and control of a MMA polymerization reactor under deterministic and uncertain demand characteristics. Since chemical process design must be flexible and robust enough to accommodate for process uncertainties, a two-stage programming formulation which deals with demand uncertainties with discrete distributions was proposed.

The two-stage programming problem was solved, and interesting observations can be drawn from such a solution, and from its comparison versus a deterministic approach. The hourly profit (objective function value) obtained by the complete two-stage programming formulation was slightly better than the equivalent addition of the individual solutions of different scenarios using the design results determined in the original deterministic problem as fixed parameters. However, when the design variables (including the determined steady states) resulting from the two-stage programming solution, were also fixed and different demand scenarios were solved independently, significantly better solutions than those provided using the deterministic design were found. The comparison was made using identical conditions (same constraints, objective function, solver and solver options, computer hardware, etc.), including the same initialization point.

This work represents another step in the simultaneous solution of process and grade design, scheduling, and optimal control. The next steps can take many directions: process design beyond reactor design, implementation of close-loop control schemes, inclusion of more complex scheduling models, solution of larger dynamic models by optimization decomposition techniques, parallel computing for scheduling and control, integration of planning, scheduling and control, inclusion of uncertainty in model and other market parameters, and/or continuous probability distributions for uncertain quantities based on stochastic optimization formulations, extension of most of the past research points to deal with batch plants. Recent developments and improvements of large scale MINLP problem ${ }^{30}$ solvers further encourages the exploration of all these research possibilities. 
Table 1: Objective function parameters

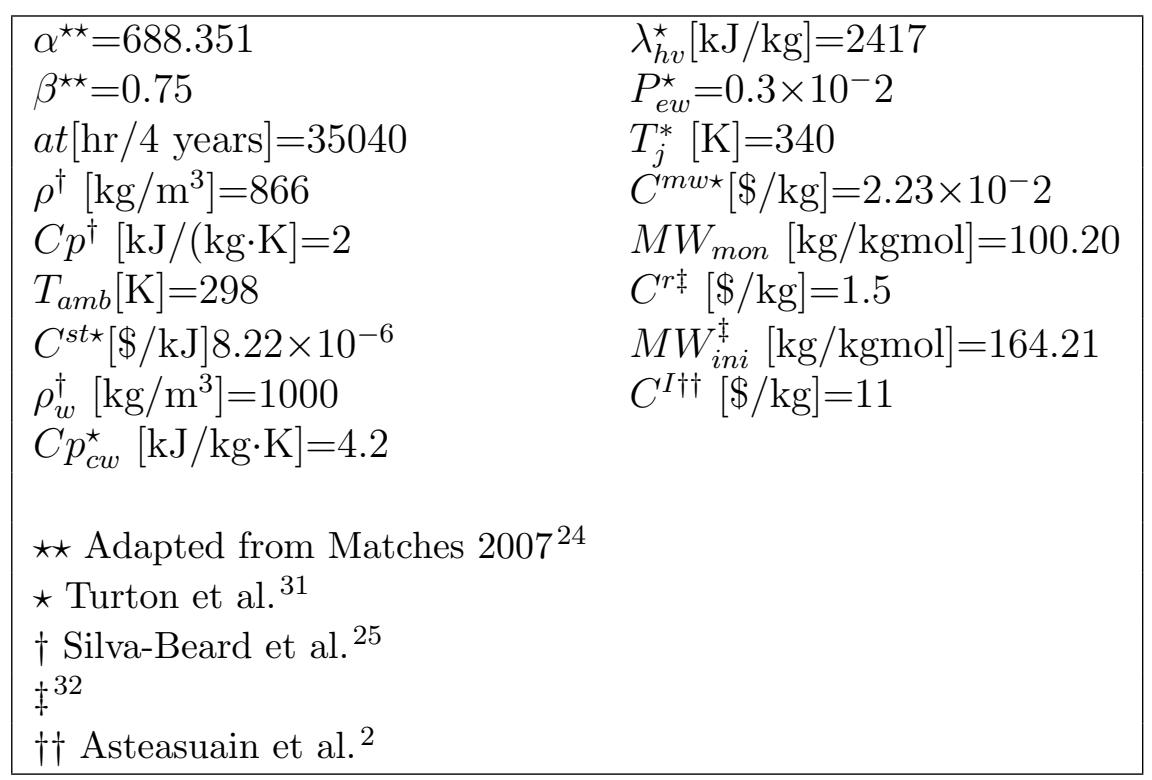

Table 2: Physical Constants

\begin{tabular}{|l|}
\hline$U=720 \mathrm{~kJ} /\left(\mathrm{h} \cdot \mathrm{K} \cdot \mathrm{m}^{2}\right)$ \\
$R=8.314 \mathrm{~kJ} /(\mathrm{kgmol} \cdot \mathrm{K})$ \\
$-\Delta \mathrm{H}=57800 \mathrm{~kJ} / \mathrm{kgmol}$ \\
$E_{p}=1.8283 \times 10^{4} \mathrm{~kJ} / \mathrm{kgmol}$ \\
$E_{I}=1.2877 \times 10^{5} \mathrm{~kJ} / \mathrm{kgmol}$ \\
$E_{f m}=7.4478 \times 10^{4} \mathrm{~kJ} / \mathrm{kgmol}$ \\
$E_{t c}=2.9442 \times 10^{3} \mathrm{~kJ} / \mathrm{kgmol}$ \\
$E_{t d}=2.9442 \times 10^{3} \mathrm{~kJ} / \mathrm{kgmol}$ \\
$A_{p}=1.77 \times 10^{9} \mathrm{~m}^{3} /(\mathrm{kgmol} \cdot \mathrm{h})$ \\
$A_{I}=3.792 \times 10^{18} 1 / \mathrm{h}$ \\
$A_{f m}=1.0067 \times 10^{15} \mathrm{~m}^{3} /(\mathrm{kgmol} \cdot \mathrm{h})$ \\
$A_{t c}=3.8223 \times 10^{10} \mathrm{~m}^{3} /(\mathrm{kgmol} \cdot \mathrm{h})$ \\
$A_{t d}=3.1457 \times 10^{11} \mathrm{~m}^{3} /(\mathrm{kgmol} \cdot \mathrm{h})$ \\
\hline
\end{tabular}

Table 3: pMMA Grade Information

\begin{tabular}{|lccccc|}
\hline & Grade A & Grade B & Grade C & Grade D & Grade E \\
\hline Desired $M W[\mathrm{~kg} / \mathrm{kgmol}]$ & 15000 & 20000 & 25000 & 35000 & 45000 \\
Demand $[\mathrm{kg} / \mathrm{hr}]$ & 1.6 & 1.4 & 1.0 & 0.8 & 0.6 \\
Price $[\$ / \mathrm{kg}]$ & 1.20 & 1.30 & 1.50 & 1.60 & 1.65 \\
Inv. Cost $[\$ / \mathrm{hr}-\mathrm{kg})]$ & $1.20 \times 10^{-3}$ & $1.50 \times 10^{-3}$ & $1.60 \times 10^{-3}$ & $1.60 \times 10^{-3}$ & $1.65 \times 10^{-3}$ \\
\hline
\end{tabular}


Table 4: CSTR design variable results

\begin{tabular}{|l|}
\hline$F=0.390 \mathrm{~m}^{3} / \mathrm{h}$ \\
$F_{c w}=0.010 \mathrm{~m}^{3} / \mathrm{h}$ \\
$C_{\text {min }}=0.767 \mathrm{kgmol} / \mathrm{m}^{3}$ \\
$C_{\text {Iin }}=10.000 \mathrm{kgmol} / \mathrm{m}^{3}$ \\
$T_{\text {in }}=344.8 \mathrm{~K}$ \\
$T_{w 0}=298.0 \mathrm{~K}$ \\
$A=15.120 \mathrm{~m}^{2}$ \\
$V=2.073 \mathrm{~m}^{3}$ \\
$V_{0}=0.415 \mathrm{~m}^{3}$
\end{tabular}

Table 5: pMMA Steady State Results

\begin{tabular}{|lccccc|}
\hline & Grade A & Grade B & Grade C & Grade D & Grade E \\
\hline$C^{m}\left[\mathrm{kgmol} / \mathrm{m}^{3}\right]$ & 0.4162 & 0.4749 & 0.5216 & 0.6070 & 0.6760 \\
$C^{I} \times 10^{3}\left[\mathrm{kgmol} / \mathrm{m}^{3}\right]$ & 1.5064 & 0.9056 & 0.5833 & 0.2195 & 0.0661 \\
$T^{R}[\mathrm{~K}]$ & 348.1 & 347.3 & 346.7 & 345.7 & 344.8 \\
$Q^{I} \times 10^{4}\left[\mathrm{~m}^{3} / \mathrm{h}\right]$ & 1.1486 & 0.6598 & 0.4105 & 0.1455 & 0.0419 \\
$X[\%]$ & 0.4574 & 0.3809 & 0.3199 & 0.2089 & 0.1186 \\
$M W[\mathrm{~kg} / \mathrm{kgmol}]$ & 15200 & 20200 & 24800 & 34800 & 44800 \\
\hline
\end{tabular}

Table 6: Scheduling variables at the optimal solution. The objective function value is $\$$ 2.32/hr and $544.7 \mathrm{~h}$ of total cycle time.

\begin{tabular}{|cccccc|}
\hline Product & Process T $[\mathrm{h}]$ & production $[\mathrm{kg}]$ & Trans T $[\mathrm{h}]$ & T start $[\mathrm{h}]$ & T end $[\mathrm{h}]$ \\
\hline$A$ & 95.25 & 1307.34 & 14.21 & 0 & 109.47 \\
$E$ & 137.32 & 490.25 & 1.74 & 109.57 & 248.52 \\
$D$ & 104.16 & 653.67 & 1.26 & 248.52 & 353.95 \\
$C$ & 85.07 & 817.08 & 2.58 & 353.94 & 441.59 \\
$B$ & 100.06 & 1143.92 & 3.07 & 441.59 & 544.73 \\
\hline
\end{tabular}

Table 7: Contributions to the objective function for the deterministic example.

\begin{tabular}{|ll|}
\hline Objective Function Term & Contribution $[\$ / \mathrm{hr}]$ \\
\hline Sales & 11.27 \\
Reactor ( 4 yr amortization) & 2.22 \\
Feed Stream Heating & 0.26 \\
Cooling Water & 1.32 \\
Inventories & 2.63 \\
Offspec during transitions & 2.53 \\
\hline
\end{tabular}


Table 8: Demand Scenarios in example 2.

\begin{tabular}{|lcccccc|}
\hline & Grade A & Grade B & Grade C & Grade D & Grade E & Probability \\
\hline Demand scenario 1 $[\mathrm{kg} / \mathrm{h}]$ & 1.6 & 1.4 & 1.0 & 0.8 & 0.6 & 0.30 \\
Demand scenario 2 $[\mathrm{kg} / \mathrm{h}]$ & 1.6 & 1.4 & 1.0 & 0.8 & 0.9 & 0.20 \\
Demand scenario 3 $[\mathrm{kg} / \mathrm{h}]$ & 1.6 & 1.4 & 0.5 & 0.8 & 0.6 & 0.20 \\
Demand scenario 4 $[\mathrm{kg} / \mathrm{h}]$ & 1.6 & 1.4 & 0.5 & 0.8 & 0.9 & 0.15 \\
Demand scenario 5 $[\mathrm{kg} / \mathrm{h}]$ & 4.8 & 1.4 & 0.5 & 0.8 & 0.9 & 0.15 \\
\hline
\end{tabular}

Table 9: CSTR design variable results in example 2

\begin{tabular}{|l|}
\hline$F=0.431 \mathrm{~m}^{3} / \mathrm{h}$ \\
$F_{c w}=0.0100 \mathrm{~m}^{3} / \mathrm{h}$ \\
$C_{\text {min }}=0.809 \mathrm{kgmol} / \mathrm{m}^{3}$ \\
$C_{\text {Iin }}=10.000 \mathrm{kgmol} / \mathrm{m}^{3}$ \\
$T_{\text {in }}=344.87 \mathrm{~K}$ \\
$T_{w 0}=298.00 \mathrm{~K}$ \\
$A=15.370 \mathrm{~m}^{2}$ \\
$V=2.125 \mathrm{~m}^{3}$ \\
$V_{0}=0.425 \mathrm{~m}^{3}$ \\
\hline
\end{tabular}

Table 10: pMMA Steady State Results in example 2

\begin{tabular}{|lccccc|}
\hline & Grade A & Grade B & Grade C & Grade D & Grade E \\
\hline$C^{m}\left[\mathrm{kgmol} / \mathrm{m}^{3}\right]$ & 0.4413 & 0.5045 & 0.5547 & 0.6487 & 0.7181 \\
$C^{I} \times 10^{3}\left[\mathrm{kgmol} / \mathrm{m}^{3}\right]$ & 1.4945 & 0.9047 & 0.5851 & 0.2112 & 0.0653 \\
$T^{R}[\mathrm{~K}]$ & 348.93 & 348.04 & 347.34 & 346.02 & 345.05 \\
$Q^{I} \times 10^{4}\left[\mathrm{~m}^{3} / \mathrm{h}\right]$ & 1.2798 & 0.7336 & 0.4553 & 0.1529 & 0.0450 \\
$X[\%]$ & 0.4545 & 0.3764 & 0.3143 & 0.1981 & 0.1124 \\
$M W[\mathrm{~kg} / \mathrm{kgmol}]$ & 15200 & 20200 & 24800 & 35200 & 44800 \\
\hline
\end{tabular}

Table 11: Scenario by scenario results using the two-stage programming formulation. The weighted objective function is $2.25 \$ / \mathrm{h}$. Scenario profits, sales, and costs are in $\$ / \mathrm{h}$; cycle and total transition times are in hours.

\begin{tabular}{|cccccccc|}
\hline Scenario & Sequence & $\begin{array}{c}\text { Cycle } \\
\text { time }\end{array}$ & $\begin{array}{c}\text { Trans. } \\
\text { time }\end{array}$ & $\begin{array}{c}\text { Sales } \\
\text { Design } \\
\text { costs }\end{array}$ & $\begin{array}{c}\text { Inventory } \\
\text { costs }\end{array}$ & $\begin{array}{c}\text { Trans. } \\
\text { costs }\end{array}$ \\
\hline 1 & $A \rightarrow E \rightarrow D \rightarrow C \rightarrow B$ & 542 & 20.97 & 11.27 & 3.87 & 2.69 & 2.69 \\
2 & $A \rightarrow E \rightarrow D \rightarrow C \rightarrow B$ & 546 & 20.97 & 12.01 & 3.87 & 2.80 & 2.67 \\
3 & $A \rightarrow B \rightarrow C \rightarrow D \rightarrow E$ & 652 & 27.74 & 10.14 & 3.87 & 2.92 & 2.92 \\
4 & $A \rightarrow E \rightarrow D \rightarrow C \rightarrow B$ & 561 & 20.97 & 10.88 & 3.87 & 2.60 & 2.60 \\
5 & $A \rightarrow E \rightarrow D \rightarrow C \rightarrow B$ & 598 & 21.86 & 14.24 & 3.87 & 2.96 & 2.50 \\
\hline
\end{tabular}


Table 12: Scheduling and control results using the deterministic design. The resulting profit using the same probabilities (weights) as in the two-stage programming formulation, is $2.23 \$ / \mathrm{hr}$. Scenario profits, sales, and costs are in $\$ / \mathrm{h}$; cycle and total transition times are in hours.

\begin{tabular}{|cccccccc|}
\hline Scenario & Sequence & $\begin{array}{c}\text { Cycle } \\
\text { time }\end{array}$ & $\begin{array}{c}\text { Trans. } \\
\text { time }\end{array}$ & $\begin{array}{c}\text { Sales } \\
\text { Design } \\
\text { costs }\end{array}$ & $\begin{array}{c}\text { Inventory } \\
\text { costs }\end{array}$ & $\begin{array}{c}\text { Trans. } \\
\text { costs }\end{array}$ \\
\hline 1 & $A \rightarrow E \rightarrow D \rightarrow C \rightarrow B$ & 554 & 22.86 & 11.27 & 3.80 & 2.67 & 2.48 \\
2 & $A \rightarrow E \rightarrow D \rightarrow C \rightarrow B$ & 556 & 22.86 & 11.27 & 3.80 & 2.68 & 2.47 \\
3 & $A \rightarrow E \rightarrow D \rightarrow C \rightarrow B$ & 562 & 22.86 & 10.14 & 3.80 & 2.45 & 2.45 \\
4 & $A \rightarrow E \rightarrow D \rightarrow C \rightarrow B$ & 580 & 22.86 & 10.61 & 3.80 & 2.58 & 2.37 \\
5 & $A \rightarrow E \rightarrow D \rightarrow C \rightarrow B$ & 627 & 22.86 & 12.07 & 3.80 & 2.76 & 2.19 \\
\hline
\end{tabular}

Table 13: Scheduling and control results using the two-stage programming design. The weighted objective function is $2.41 \$ / \mathrm{h}$. Scenario profits, sales, and costs are in $\$ / \mathrm{h}$; cycle and total transition times are in hours.

\begin{tabular}{|cccccccc|}
\hline Scenario & Sequence & $\begin{array}{c}\text { Cycle } \\
\text { time }\end{array}$ & $\begin{array}{c}\text { Trans. } \\
\text { time }\end{array}$ & Sales & $\begin{array}{c}\text { Design } \\
\text { costs }\end{array}$ & $\begin{array}{c}\text { Inventory } \\
\text { costs }\end{array}$ & $\begin{array}{c}\text { Trans. } \\
\text { costs }\end{array}$ \\
\hline 1 & $A \rightarrow E \rightarrow D \rightarrow C \rightarrow B$ & 542 & 20.93 & 11.27 & 3.87 & 2.68 & 2.68 \\
2 & $A \rightarrow E \rightarrow D \rightarrow C \rightarrow B$ & 554 & 20.93 & 12.01 & 3.87 & 2.83 & 2.62 \\
3 & $A \rightarrow E \rightarrow D \rightarrow C \rightarrow B$ & 570 & 20.93 & 10.14 & 3.87 & 2.55 & 2.55 \\
4 & $A \rightarrow E \rightarrow D \rightarrow C \rightarrow B$ & 560 & 20.93 & 10.88 & 3.87 & 2.59 & 2.59 \\
5 & $A \rightarrow E \rightarrow D \rightarrow C \rightarrow B$ & 590 & 20.93 & 14.25 & 3.87 & 2.92 & 2.46 \\
\hline
\end{tabular}




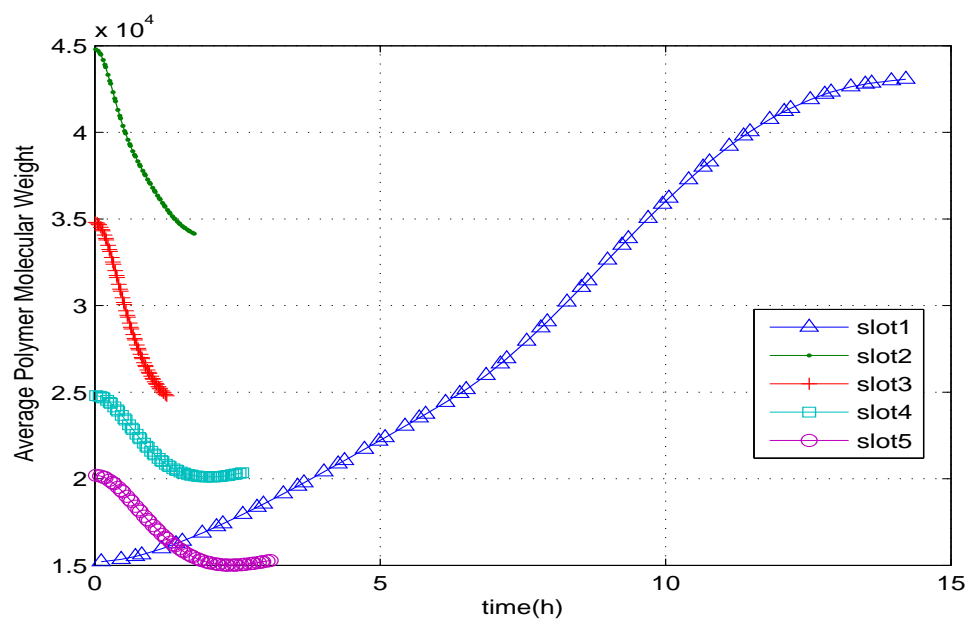

(a)

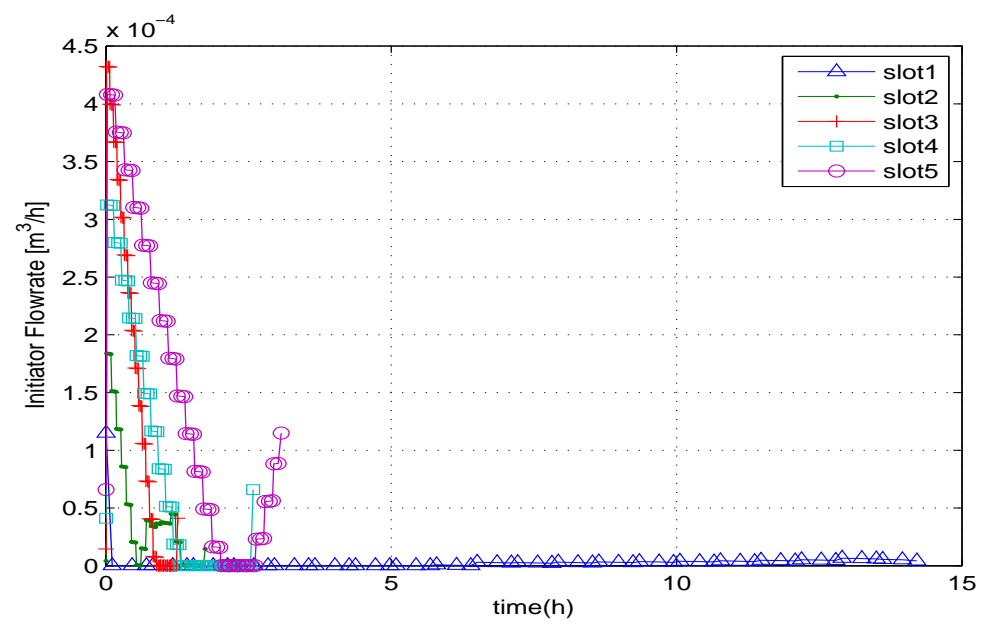

(b)

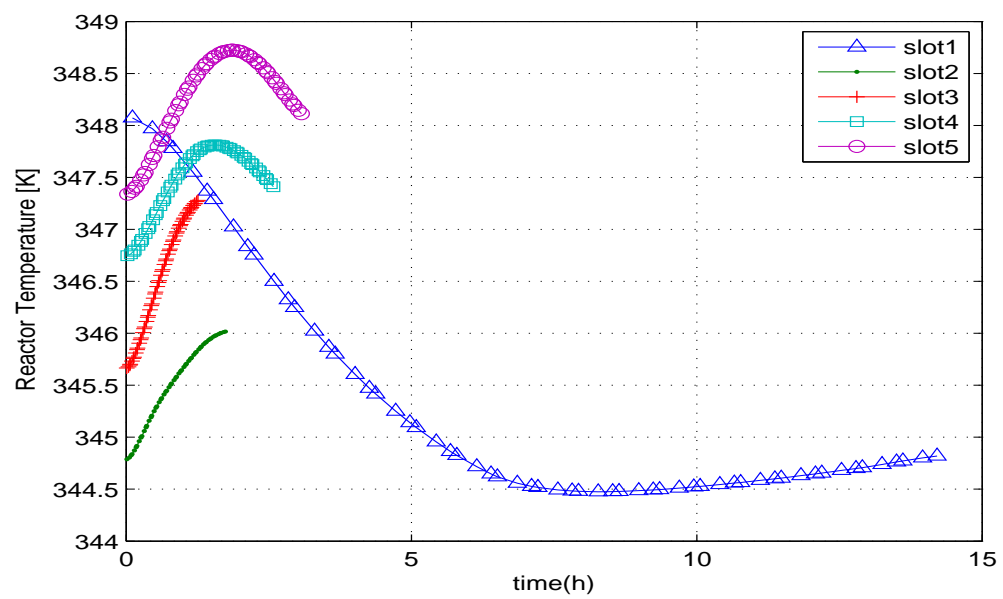

(c)

Figure 1: Dynamic Transitions in the pMMA CSTR, obtained through deterministic procedures: (a) Average molecular weight (b) Manipulated variable (c) Reactor temperature. 


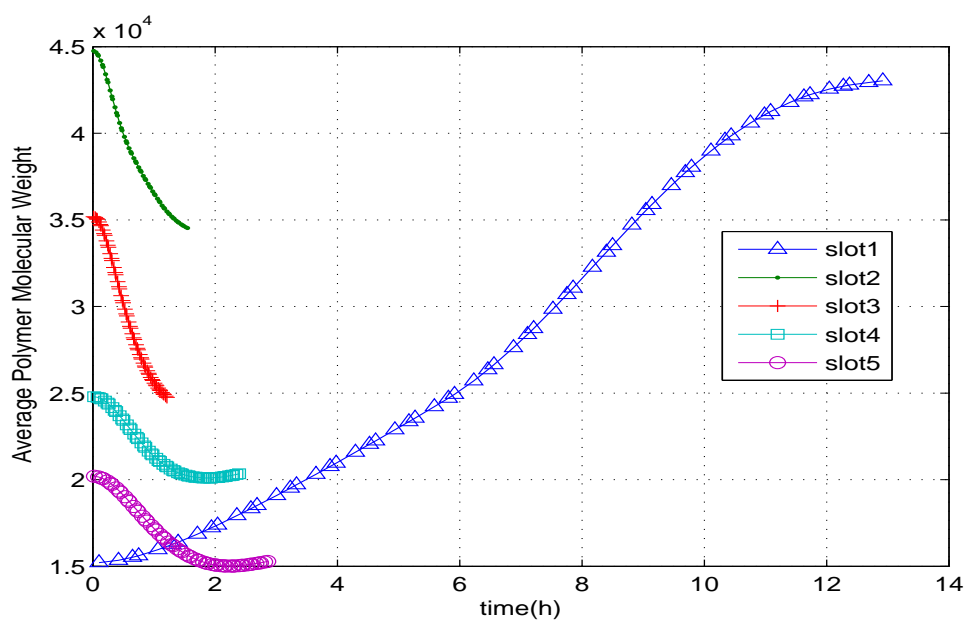

(a)

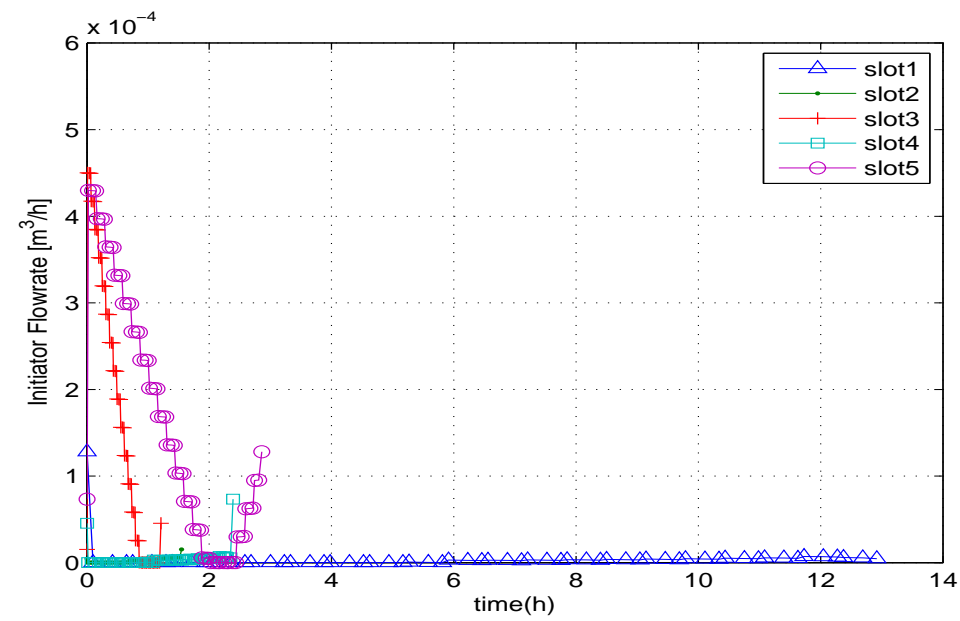

(b)

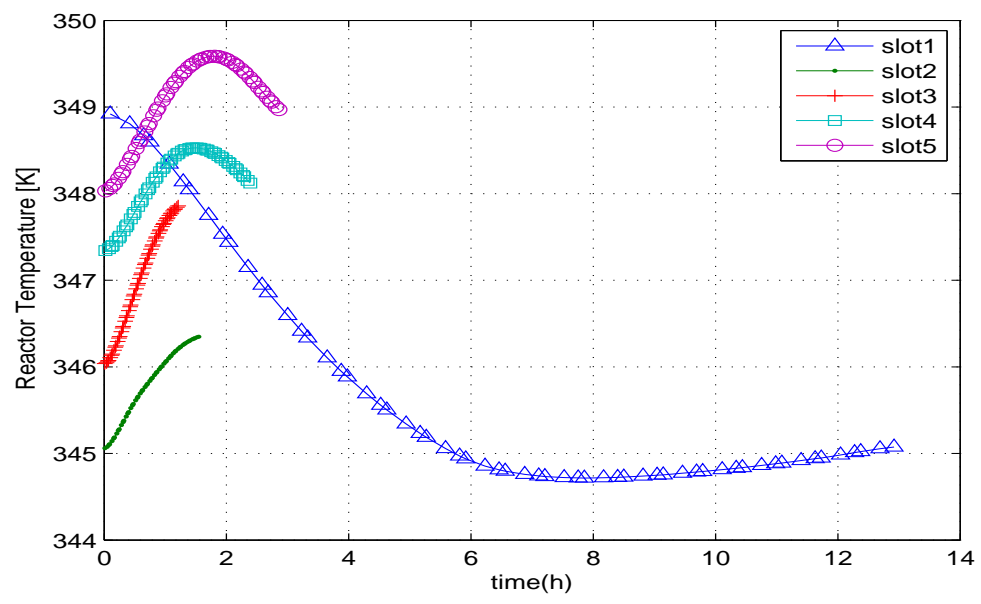

(c)

Figure 2: Dynamic Transitions in the pMMA CSTR, obtained by simultaneous scheduling and optimal control, using as fixed design the one obtained in the multiperiod example: (a) Average molecular weight (b) Manipulated variable (c) Reactor temperature. 


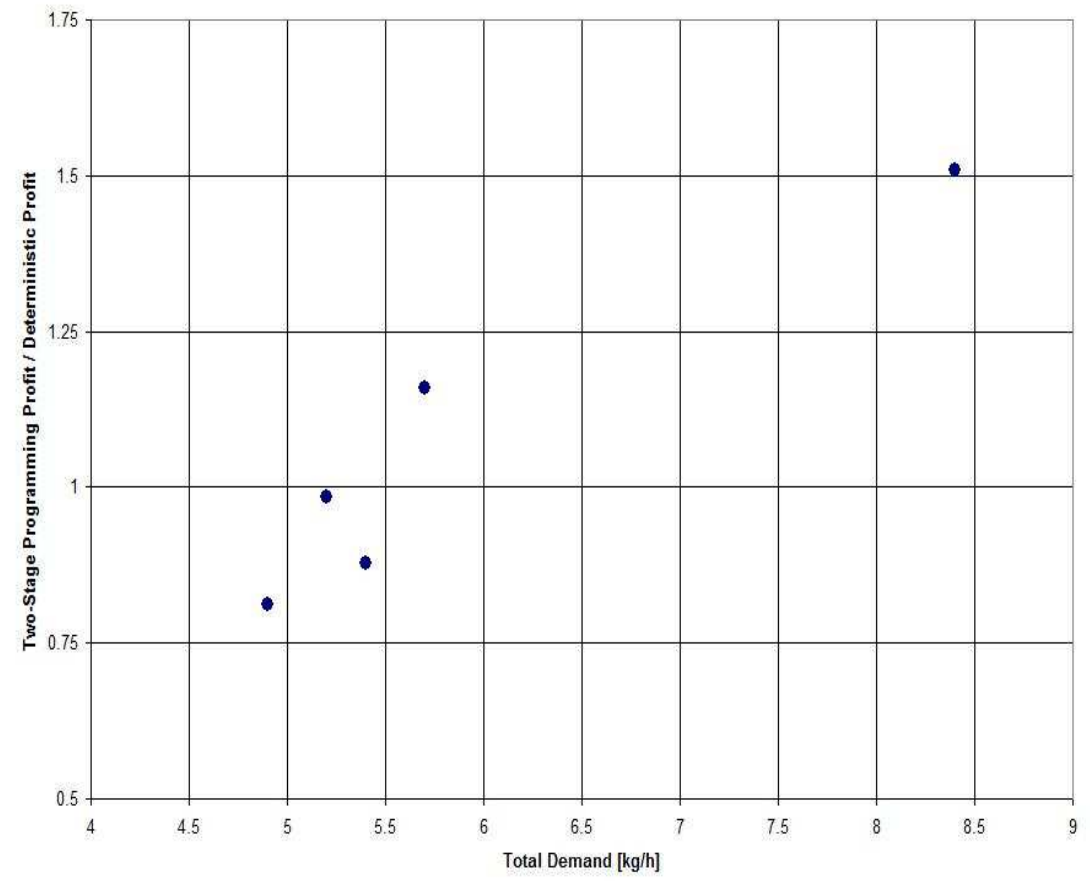

Figure 3: Relative performance two-stage programming approach vs. deterministic approach 


\section{References}

[1] B.V. Mishra, E. Mayer, J. Raisch, and A. Kienle. Short-Term Scheduling of Batch Processes. A Comparative Study of Different Approaches. Ind. Eng. Chem. Res., 44:4022-4034, 2005.

[2] M. Asteasuain, A. Bandoni, and C. Sarmoria A. Brandolin. Simultaneous process and control system design for grade transition in styrene polymerization. Chem. Eng. Sci., 61:3362-3378, 2006.

[3] A. Flores-Tlacuahuac and L.T. Biegler. Simultaneous control and process design during optimal polymer grade transition operations. Accpeted for publication in Comput. Chem. Eng., 2007.

[4] A. Flores-Tlacuahuac and L.T. Biegler. Simultaneous mixed-integer dynamic optimzation for integrated desgin and control. Comput. Chem. Eng., 31:588-600, 2007.

[5] L.T. Biegler, I.E. Grossmann, and Westerberg A.W. Systematic Methods of Chemical Process Design. Prentice Hall PTR, 1980.

[6] S Heo, K. Lee, I. Lee, and J. Park. A new algorithm for cyclic scheduling and design of multipurpose batch plants. Ind. Eng. Chem. Res., 42(4):836-846, 2003.

[7] T. Bhatia and L.T. Biegler. Dynamic optimization in the design and scheduling of multiproduct batch plants. Ind. Eng. Chem. Res., 35(7):2234-2246, 1996.

[8] T. Bhatia and L.T. Biegler. Dynamic optimization for batch design and scheduling with process model uncertainty. Ind. Eng. Chem. Res., 36(9):3708-3717, 1997.

[9] S. Terrazas-Moreno, A. Flores-Tlacuahuac, and I.E. Grossmann. Simultaneous Cyclic Scheduling and Optimal Control of Polymerization Reactors. AICHE J., 54(1):163$182,2008$. 
[10] S. Terrazas-Moreno, A. Flores-Tlacuahuac, and I.E. Grossmann. A Lagrangean Approach for the Scheduling and Optimal Control of Polymerization Reactors. AICHE J., 53(9):2301-2315, 2007.

[11] A. Flores-Tlacuahuac and I.E. Grossmann. Simultaneous Cyclic Scheduling and Control of a Multiproduct CSTR. Ind. Eng. Chem. Res., 45(20):6698-6712, 2006.

[12] R.H. Nystrom, R. Franke, I.Harjunkoski, and A.Kroll. Production Campaign Planning including Grade Transition Sequencing and Dynamic Optimization. Comput. Chem. Eng., 29(10):2163-2179, 2005.

[13] R.H. Nystrom, I.Harjunkiski, and A.Kroll. Production Optimization for continuously operated processes with optimal operation and scheduling of multiple units. Comput. Chem. Eng., 30:392-406, 2006.

[14] A. Prata, J. Oldenburg, W. Marquardt, and A. Kroll R. Nystrom. Integrated Scheduling and Dynamic Optimization of Grade Transitions for a Continuous Polymerization Reactor. Comput. Chem. Eng., 2007.

[15] R. Mahadevan, F.J. III Doyle, and A.C. Allcock. Control-Relevant Scheduling of Polymer Grade Transitions. AICHE J., 48(8):1754-1764, 2002.

[16] D. Feather, D. Harrell, R. Liberman, and F.J. Doyle. Hybrid Approach to Polymer Grade Transition Control. AICHE J., 50(10):2502-2513, 2004.

[17] J. Acevedo and E.N. Pistikopoulos. A parametric MINLP algorithm for process synthesis problems under uncertainty. Ind. Eng. Chem. Res., 35(1):147-158, 1996.

[18] N.V. Sahinidis. Optimization under uncertainty: state-of-the-art and opportunities. Comput. Chem. Eng., 28(6-7):971-983, 2004.

[19] J.R. Birge and F. Louveaux. Introduction to Stochastic Programming. SpringerVerlag, New Jersey, 2007. 
[20] H. Arellano-Garcia. Chance Constrained Optimization of Process Systems under Uncertainty. Ph.D. Thesis, Technical University of Berlin, http://opus.kobv.de/tuberlin/volltexte/2006/1412, 2006.

[21] U.A. Ozturk, M. Mazumdar, and B.A. Norman. A Solution to the Stochastic Unit Commitment Problem Using Chance Constrained Programming. IEEE Transactions on Power Systems, pages 1-10, 2004.

[22] A. Prekopa. Stochastic Programming. Kluwer Academic Publishers, 1995.

[23] L.T. Biegler. Optimization strategies for complex process models. Advances in Chemical Engineering, 18:197-256, 1992.

[24] . http://www.matche.com/EquipCost/Reactor.htm, 2006.

[25] S. Silva-Beard and A. Flores-Tlacuahuac. Effects of Process Design/Operation on the Steady-State Operability of a Methyl-Methacrylate Polymerization Reactor. Ind. Eng. Chem. Res., 38:4790-4804, 1999.

[26] B. Finlayson. Nonlinear Analysis in Chemical Engineering. McGraw-Hill, Iguazu, 1980.

[27] Villadsen, J., and M.Michelsen. Solution of Differential Equations Models by Polynomial Approximation. Prentice-Hall, 1978.

[28] http://www.gams.com/docs/document.htm.

[29] M.A. Duran and I.E. Grossmann. An outer approximation algorithm for a class of mixed integer nonlinear programs. Mathematical Programming, 36:307, 1986.

[30] P. Bonami, L.T. Biegler, A. Conn, and C. Laird J. Lee A. Lodi F. Magot S. Nicolas A. Waechter G. Cornuejols, I.E. Grossmann. An algorithmic framework for convex mixed integer nonlinear programs. To appear in Discrete Optimization, 2007.

[31] R. Turton, R.C. Bailie, W.B. Whiting, and J.A. Shaeiwitz. Analysis, Synthesis and Design of Chemical Processes. Prentice-Hall, New Jersey, 2003. 
[32] http://www.the-innovation-group.com/, 2003. 


\section{Appendix}

The indices, decision variables and system parameters used in the SSC MIDO problem formulation are as follows:

1. Indices

Products

$$
i, p=1, \ldots N_{p}
$$

Slots $k=1, \ldots N_{s}$

Finite elements $f=1, \ldots N_{f e}$

Collocation points

$c, l=1, \ldots N_{c p}$

System states

$n=1, \ldots N_{x}$

Manipulated variables

$m=1, \ldots N_{u}$

Demand scenarios

$q=1, \ldots N_{d s}$

2. Decision variables

$y_{i k} \quad$ Binary variable to denote if product $i$ is assigned to slot $k$

$p_{k} \quad$ Processing time at slot $k$

$t_{k}^{e} \quad$ Final time at slot $k$

$t_{k}^{s} \quad$ Start time at slot $k$

$t_{f c k} \quad$ Time at finite element $f$ and collocation point $c$ of slot $k$

$G_{i} \quad$ Production rate

Tc Cyclic time $[\mathrm{h}]$

$x_{f c k}^{n} \quad n$-th system state in finite element $f$ and collocation point $c$ of slot $k$

$\dot{x}_{f l k}^{n} \quad$ Value of $n$-th state derivative with respect to time in finite element $f$ and collocation point $l$ of slot $k$

$u_{f c k}^{m} \quad m$-th manipulated variable in finite element $f$ and collocation point $c$ of slot $k$ 


\begin{tabular}{|c|c|}
\hline$W_{i}$ & Amount produced of each product $[\mathrm{kg}]$ \\
\hline$\theta_{i k}$ & Processing time of product $i$ in slot $k$ \\
\hline$\theta_{k}^{t}$ & Transition time at slot $k$ \\
\hline$\Theta_{i}$ & Total processing time of product $i$ \\
\hline$x_{o, f k}^{n}$ & $n$-th state value at the beginning of the finite element $f$ of slot $k$ \\
\hline $\bar{x}_{k}^{n}$ & Desired value of the $n$-th state at the end of dynamic transition of slot $k$ \\
\hline $\bar{u}_{k}^{m}$ & $\begin{array}{l}\text { Desired value of the } m \text {-th manipulated variable at the end of dynamic } \\
\text { transition of slot } k\end{array}$ \\
\hline$x_{i n, k}^{n}$ & $n$-th state value at the beginning of dynamic transition of slot $k$ \\
\hline$u_{i n, k}^{n}$ & $\begin{array}{l}m \text {-th manipulated variable value at the beginning of dynamic transition } \\
\text { of slot } k\end{array}$ \\
\hline$x_{s s, i}^{n}$ & $n$-th state value at steady state of product $i$ \\
\hline$u_{s s, i}^{m}$ & $m$-th manipulated variable value of product $i$ \\
\hline$X_{f c k}$ & Conversion in finite element $f$ and collocation point $c$ of slot $k$ \\
\hline$M W D_{f c k}$ & $\begin{array}{l}\text { Molecular Weight Distribution in finite element } f \\
\text { and collocation point } c \text { of slot } k\end{array}$ \\
\hline$T_{\text {in }}$ & Monomer feed stream feeding temperature $[\mathrm{K}]$ \\
\hline$T_{w}$ & Cooling water feeding temperature $[\mathrm{K}]$ \\
\hline$F_{\text {mon }}$ & Monomer feed stream flow rate $\left[\mathrm{m}^{3} / \mathrm{h}\right]$ \\
\hline$F_{c w}$ & Cooling water flow rate $\left[\mathrm{m}^{3} / \mathrm{h}\right]$ \\
\hline$C_{\min }$ & Monomer feed stream concentration $\left[\mathrm{kmol} / \mathrm{m}^{3}\right]$ \\
\hline$C_{\text {Iin }}$ & Initiator feed stream concentration $\left[\mathrm{kmol} / \mathrm{m}^{3}\right]$ \\
\hline$V$ & Reactor volume $\left[\mathrm{m}^{3}\right]$ \\
\hline$V_{0}$ & Jacket volume $\left[\mathrm{m}^{3}\right]$ \\
\hline$A$ & Surface area for heat exchange $\left[\mathrm{m}^{2}\right]$ \\
\hline$z$ & Control-related variables \\
\hline$s c$ & Scheduling-related variables \\
\hline & Design-related variables \\
\hline
\end{tabular}




\section{Parameters}

\begin{tabular}{|c|c|}
\hline$N_{p}$ & Number of products \\
\hline$N_{s}$ & Number of slots \\
\hline$N_{f e}$ & Number of finite elements \\
\hline$N_{c p}$ & Number of collocation points \\
\hline$N_{x}$ & Number of system states \\
\hline$N_{u}$ & Number of manipulated variables \\
\hline$N_{d s}$ & Number of demand scenarios \\
\hline$D_{i}$ & Demand rate $[\mathrm{kg} / \mathrm{h}]$ \\
\hline$\theta_{q}$ & Uncertain parameters values at period $q$ \\
\hline$\alpha$ & Pre-exponential factor of reactor volume-cost correlation $\left[\$ / \mathrm{m}^{3}\right]$ \\
\hline$\beta$ & Exponential factor of volume-cost correlation \\
\hline at & Number of hours in the four year amortization period $[\mathrm{h}]$ \\
\hline$C_{i}^{p}$ & Price of products $[\$ / \mathrm{kg}]$ \\
\hline$C_{i}^{s}$ & Cost of inventory $[\$ / \mathrm{kg}-\mathrm{hr}]$ \\
\hline$C^{r}$ & Cost of raw material $[\$ /$ lt of feed solution] \\
\hline$C^{I}$ & Cost of initiator $[\$ /$ lt of feed solution] \\
\hline$C^{s t}$ & Cost of providing energy from steam $[\$ / \mathrm{kJ}]$ \\
\hline$C^{c w}$ & Cost of supplying cooling water $[\$ / \mathrm{kg}]$ \\
\hline$C^{m w}$ & Unit cost of replacing cooling water $[\$ / \mathrm{kg}]$ \\
\hline$h_{f k}$ & Length of finite element $f$ in slot $k$ \\
\hline$\Omega_{c c}$ & Matrix of Radau quadrature weights \\
\hline $\bar{x}_{k}^{n}$ & Desired value of the $n$-th system state at slot $k$ \\
\hline$\theta^{\max }$ & Upper bound on processing time \\
\hline$\omega_{q}$ & Probability associated with scenario $q$ \\
\hline$M W D_{s s, i}$ & Desired molecular weight distribution of grade $i$ \\
\hline
\end{tabular}




\begin{tabular}{|c|c|}
\hline$x_{\min }^{n}, x_{\max }^{n}$ & Minimum and maximum value of the state $x^{n}$ \\
\hline$u_{\min }^{m}, u_{\max }^{m}$ & Minimum and maximum value of the manipulated variable $u^{m}$ \\
\hline$\dot{x}_{t o l}^{n}$ & $\begin{array}{l}\text { Maximum absolute value for state derivatives at the end of dynamic } \\
\text { transition }\end{array}$ \\
\hline$x_{t o l}^{n}$ & $\begin{array}{l}\text { Maximum absolute deviation from desired final value, allowable for } \\
\text { state variable } x^{n} \text { at the end of dynamic transition }\end{array}$ \\
\hline$u_{\text {cont }}^{f}$ & Maximum absolute change for $u^{m}$ between finite elements \\
\hline$u_{\text {cont }}^{c}$ & Maximum absolute change for $u^{m}$ between collocation points \\
\hline$\gamma_{c}$ & Roots of the Lagrange orthogonal polynomial \\
\hline$Q_{\max }^{m}$ & Maximum monomer flow rate $[\mathrm{lt} / \mathrm{hr}]$ \\
\hline$Q_{\max }^{I}$ & Maximum initiator flow rate $[\mathrm{lt} / \mathrm{hr}]$ \\
\hline$T_{j}^{*}$ & $\begin{array}{l}\text { An expected jacket temperature used to calculate average heat required } \\
\text { in order to cool down water after process }\end{array}$ \\
\hline$T_{a m b}$ & Room temperature $[\mathrm{K}]$ \\
\hline$\lambda_{h v}$ & Water latent heat of vaporization $[\mathrm{kj} / \mathrm{kg}]$ \\
\hline$P_{c} w$ & Percent of water lost during cooling operations [\%] \\
\hline$\rho$ & Monomer feed stream density $\left[\mathrm{kg} / \mathrm{m}^{3}\right]$ \\
\hline$C_{p}$ & Monomer feed stream heat capacity $[\mathrm{kJ} / \mathrm{kg}-\mathrm{K}]$ \\
\hline$\rho_{w}$ & Cooling water density $\left[\mathrm{kg} / \mathrm{m}^{3}\right]$ \\
\hline$C_{p w}$ & Cooling water heat capacity $[\mathrm{kJ} / \mathrm{kg}-\mathrm{K}]$ \\
\hline$M W_{m o n}$ & Monomer molecular weight $[\mathrm{kmol} / \mathrm{kg}]$ \\
\hline$M W_{i n i}$ & Initiator molecular weight $[\mathrm{kmol} / \mathrm{kg}]$ \\
\hline$d_{\min }, d_{\max }$ & Lower and upper bounds on design variables \\
\hline$U^{p}$ & Upper bound on production \\
\hline
\end{tabular}

